\title{
Uma abordagem morfodinâmica na caracterização fisica das praias estuarinas da Baia de Paranaguá, sul do Brasil
}

\author{
Leonardo Cruz da Rosa ${ }^{1,2}$ \& Carlos Alberto Borzone ${ }^{2}$
}

\begin{abstract}
Resumo Nesse estudo, treze praias estuarinas localizadas ao longo da Baía de Paranaguá foram caracterizadas quanto a sua morfologia, composição sedimentar, regime de ondas e morfodinamismo. Morfologicamente, as praias foram caracterizadas por apresentarem uma porção superior estreita e íngreme seguido por uma planície geralmente extensa e com baixa declividade na porção inferior. Em alguns locais, a forte influência de correntes de maré inibiram a formação da planície na porção inferior da praia. A composição sedimentar da face praial variou entre areia fina muito bem selecionada a areia grossa pobremente selecionada, sendo que esse aumento no diâmetro do grão seguido pela redução do grau de seleção dos sedimentos foi observado ao longo das praias em direção ao interior da baía. Por outro lado, a proporção de frações finas do sedimento nas planícies aumentaram em direção ao interior do estuário fazendo com que estas variassem entre arenosa a lamosas. $\mathrm{O}$ regime de onda atuante nesses ambientes caracteriza-se por apresentarem ondas de baixa altura $(\mathrm{Hb}<0,25 \mathrm{~m}) \mathrm{e}$ período curto $(\mathrm{T}<5 \mathrm{~s})$. Diferenças no regime de onda foram observadas entre os períodos de maré e ao longo do estuário evidenciando um gradiente energético. Embora a aplicação dos modelos morfodinâmicos usuais tenha sido limitada pela qualidade dos dados de ondas utilizados, os perfis morfológicos observados corresponderam em parte com os descritos para ambientes de praia modificados e, principalmente, dominados por maré.
\end{abstract}

Palavras-chave: Ambientes de baixa energia, morfologia, granulometria, regime de ondas, estuário.

\begin{abstract}
A morphodinamical approach in the phisical characterization of the estuarine beaches from Paranaguá Bay, southern Brazil. In this study, thirteen estuarine sandy beaches distributed along of Paranaguá Bay were characterized regarding its morphology, sedimentary composition, wave regime and morphodynamism. The beaches were characterized by a narrow and steep beachface fronted by a wide, very low-gradient intertidal flat. The strong influence of tidal currents seems to inhibit the intertidal flat formation at some beaches. Sedimentary composition of beachface ranged from very-well sorted fine sand (beaches near to the mouth of the bay) to poor sorted coarser sand at the inner bay, while the intertidal flat ranged from sandy to muddy sediments towards to the inner estuary. Observed waves were small $(\mathrm{Hb}<0.25 \mathrm{~m})$ and of short period ( $\mathrm{T}$ $<5$ s), in general, increasing with tide and decreasing towards the inner bay. Although the application of morphodynamic models has been limited by wave data quality, observed beach profile were similar to described for tide-modified and, especially to tide-dominated beaches.
\end{abstract}

Keywords: Low-energy environment, morphology, sedimentary composition, wave regime, estuary.

INTRODUÇÃo Praias arenosas são facilmente encontradas dentro de baías e estuários no mundo inteiro. Essas praias, também conhecidas como praias estuarinas, são geralmente caracterizadas pela ação de ondas de pequena amplitude (i.e., $<0,25 \mathrm{~m}$ ) durante condições climáticas normais (Jackson et al. 2002), e podem ser consideradas como "ambientes de baixa energia". Apesar de sua presença conspícua, esses ambientes têm recebido pouca atenção por parte dos pesquisadores, os quais direcionaram seus esforços para o estudo de praias em ambientes de alta energia (Wright \& Short 1984, Masselink \& Short 1993, Short 1999). Em parte, esse descaso tem sido associado às pequenas extensões e ao baixo valor recreativo desses ambientes (Nordstrom 1992), mas também por serem erroneamente considerados similares aos ambientes de alta energia, po- rém numa escala menor (Travers 2007).

De acordo com Nordstrom (1992), praias estuarinas são depósitos intermareais de areia ou cascalho onde os processos de retrabalhamento do sedimento são dominados por ondas geradas localmente sobre uma pista curta. Ondas geradas sob essas condições são caracterizadas principalmente por seu curto período (Jackson et al. 2002). Além da menor distância da pista, a influência de outros fatores locais como a orientação da linha de costa, a configuração dos fundos adjacentes e a intensidade do vento, assumem uma maior relevância do que em zonas costeiras expostas (Nordstrom 1992, Jackson \& Nordstrom 1992). A influência desses fatores locais específicos altera a característica do regime de ondas nas praias de baixa energia modificando de forma pronunciada tanto a magnitude quanto a exten- 
são do retrabalhamento do sedimento ao longo do perfil praial (Jackson et al. 2002), podendo resultar numa grande variedade morfológica (Hegge et al. 1996).

Nordstrom \& Jackson (1992) propuseram um modelo evolutivo para praias estuarinas onde dois tipos de alterações morfológicas são identificados dependendo do processo dominante de transporte de sedimento (perpendicular ou paralelo). Dentro dessa premissa, Hegge et al. (1996) apresentaram um modelo classificatório com quatro morfotipos no qual é considerada a dimensão, a declividade, a curvatura e a granulometria das praias. Conseqüentemente, sugeriu-se que praias em ambientes de baixa energia somente podem ser classificadas em relação a sua morfologia (Makaske \& Augustinus 1998, Jackson et al. 2002, Travers 2007).

Modelos para classificação dos ambientes de praias oceânicas, ou de alta energia, são bem mais conhecidos e a relação entre o estado morfodinâmico de uma praia e as características de ondas e dos sedimentos foi primeiramente estabelecida por Wrigth \& Short (1984) utilizando o parâmetro adimensional ômega $(\Omega)$ de Dean (1973):

$$
\Omega=\frac{H b}{\varpi_{s} T}
$$

onde: $H_{b}=$ altura da onda; $\varpi_{\mathrm{s}}=$ velocidade de sedimentação da partícula e, $\mathrm{T}=$ período da onda.

A partir do emprego desse índice, as praias oceânicas em ambientes de micro-maré podem ser classificadas entre os estágios refletivos $(\Omega<2)$, intermediários $(2<\Omega<6)$ e dissipativos $(\Omega>6)$. Posteriormente, Masselink \& Short (1993) analisaram a influência da maré sobre a morfodinâmica praial e verificaram que a interação desta com a altura da onda resulta em distintas morfologias praiais. Esta interação foi resumida na formulação do índice RTR ("relative tidal range"; RTR $=\mathrm{TR} / \mathrm{Hb}$ ), o qual corresponde a razão entre a amplitude de maré (TR) e a altura da onda na arrebentação $(\mathrm{Hb})$ (Masselink \& Short 1993). De acordo com esse índice todos os ambientes de praia podem ser classificados como dominados por ondas (RTR $<3$ ) ou modificados por maré $(3<$ RTR $<15)$. Por outro lado, quando RTR $>15$ as praias tornam-se dominadas por maré e sucessivamente começam a evoluir para ambientes de planície de maré propriamente dita (Masselink \& Short 1993, Short 1996). Conseqüentemente, um modelo bidimensional conceitual, no qual são considerados os valores de $\Omega$ e de RTR, tem sido adotado para a caracterização dos estágios morfodinâmicos das praias de alta energia (Masselink \& Short 1993, Short 1996). No entanto, a utilização desse modelo para a classificação morfodinâmica dos ambientes de praias de baixa energia tem se mostrado pouco eficiente (Nordstrom 1992, Hegge et al. 1996, Masselink \& Pattiaratchi 2001, Jackson et al. 2002, Eliot et al. 2006, Travers 2007).

A ausência de um "consenso" entre os modelos propostos reforça a importância dos fatores específicos locais e ressalta a necessidade de um maior esforço no sentido de aprimorar a descrição destes ambientes particulares. Através de uma melhor compreensão dos agentes morfodinâmicos condicionantes nessas praias, será possível o desenvolvimento de um modelo descritivo, e quem sabe preditivo, eficiente para esses ambientes de baixa energia. Neste sentido, o presente estudo tem como principal objetivo caracterizar fisicamente as praias estuarinas da Baía de Paranaguá e testar o seu ajuste ao modelo morfodinâmico acima mencionado. Fatores como morfologia, características sedimentares, regime de ondas atuantes e morfodinamismo desses ambientes serão descritos e relacionados aos padrões recorrentes já descritos na literatura.

\section{MATERIAL E MÉTODOS}

Área de estudo A Baía de Paranaguá (Fig. 1), com uma extensão total de $612 \mathrm{~km}^{2}$, é melhor definida como um complexo estuarino composto essencialmente por dois corpos d'água, as baias de Paranaguá e Antonina (eixo leste-oeste) e a baía de Laranjeiras (eixo nortesul), conectando-se com o oceano através de dois canais localizados em torno da Ilha do Mel (Lana et al. 2001). Um sistema de barras submersas, as quais correspondem ao delta de maré vazante (Angulo 1999), dissipam a penetração de ondas para o interior da baía.

O complexo estuarino de Paranaguá é classificado como um estuário parcialmente misturado do tipo B com heterogeneidade lateral, particularmente na região mediana (Knoppers et al. 1987), apresentando uma profundidade média de $5,4 \mathrm{~m}$ com um volume total de água de $1.410^{9} \mathrm{~m}^{3}$ e tempo de residência de 3,5 dias (Mantovanelli et al. 2004), sendo que os padrões de circulação e estratificação apresentam variação sazonal. As marés da região são semidiurnas desiguais, em regime micromareal, com amplitudes máximas variando entre $1,7 \mathrm{~m}$ na desembocadura a $2,7 \mathrm{~m}$ no interior da baía (Marone \& Jamiyanaa 1997).

Segundo Angulo \& Araújo (1996) neste estuário encontramos dois tipos de costas sedimentares, as estuarinas dominadas pelas marés e associadas a planícies de maré cobertas por vegetação de mangue, e as associadas às desembocaduras, que apresentam sua dinâmica dominada por ondas e correntes de maré e são constituídas principalmente por praias arenosas semelhantes às oceânicas, porém com grande variabilidade temporal.

Na região, o regime de ventos é controlado pela influência da alta do Atlântico sul e pela passagem de sistemas frontais. Em condições normais são freqüentes os ventos dos setores ENE, E, ESSE e SE, com intensidade média de 4m/s (Marone \& Camargo 1994), porém, durante o deslocamento de sistemas frontais, ventos de $\mathrm{SE}$ com velocidades superiores a $25 \mathrm{~m} / \mathrm{s}$ podem ser observados (Soares et al. 1997).

Amostragem Após análises de fotos aéreas e comprovações in situ foram selecionadas 13 praias (Fig. 1) distribuídas ao longo dos dois eixos principais do complexo estuarino, as quais foram amostradas sazonalmente (verão e inverno) entre os anos de 2004 (pontos 1 a 8) e 2005 (pontos 9 a 13) sempre durante o período de baixa-mar da maré de sizígia. 


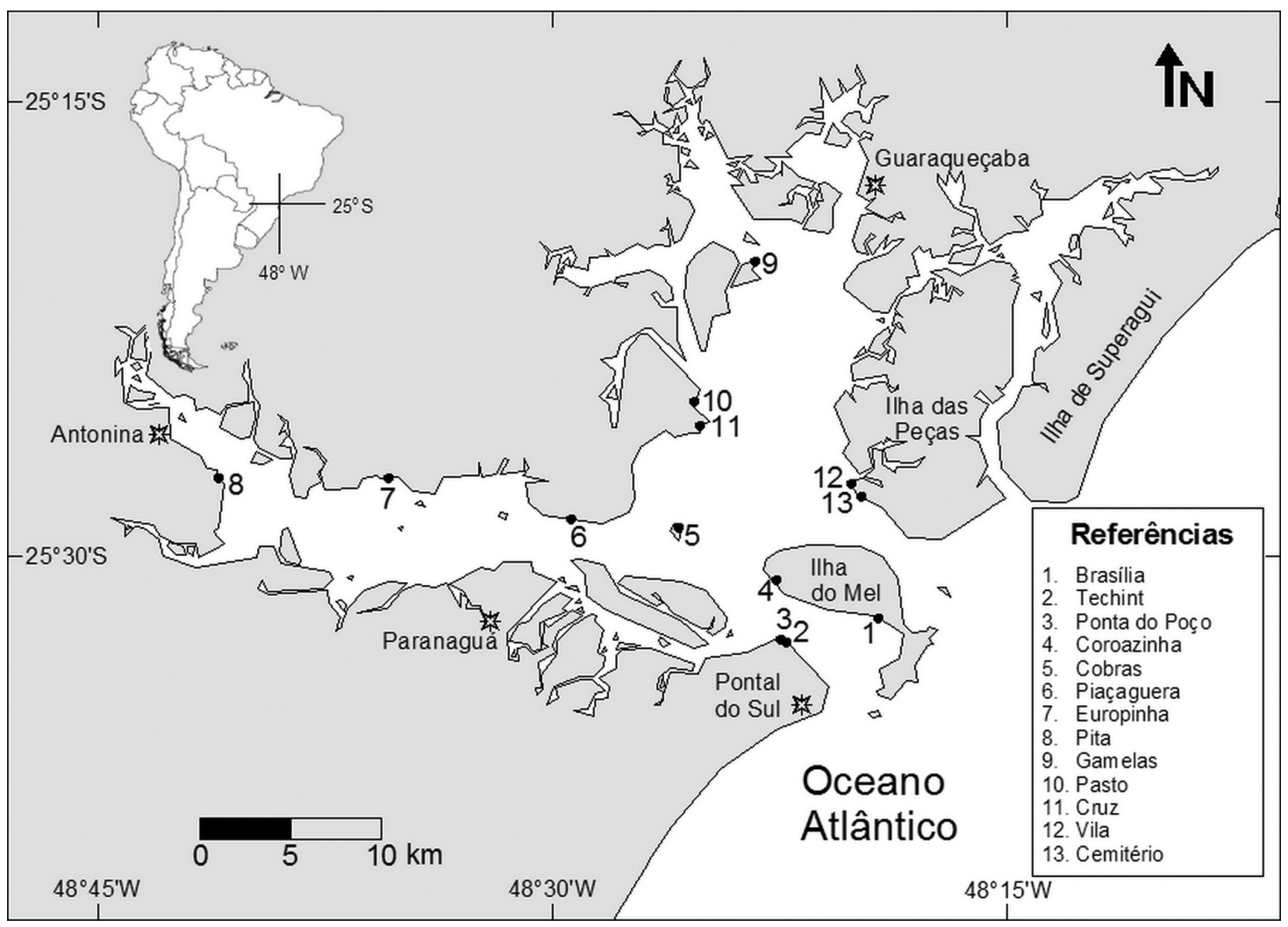

Figura 1 - Mapa da Baía de Paranaguá (Paraná, Brasil) indicando a localização das praias estudadas.

Durante cada amostragem, o perfil topográfico de cada praia foi medido com o auxílio de um nível de precisão e uma régua metrada, a partir da linha de vegetação terrestre e estendendo-se até o limite inferior da baixa-mar. Em algumas situações não foi possível medir toda a extensão do perfil devido à dificuldade de locomoção sobre a porção inferior do mesmo.

Amostras de sedimento (i.e., 10 amostras eqüidistantemente distribuídas ao longo da face praial e 2 amostras na planície) também foram coletadas com auxílio de um amostrador de PVC (4 cm de diâmetro e $10 \mathrm{~cm}$ de profundidade) para a caracterização granulométrica do ambiente. As amostras sedimentológicas foram processadas de acordo com técnicas padrões de peneiramento (Suguio 1973), sendo que os dados obtidos foram computados de acordo com o método dos momentos (Tanner 1995) e os resultados foram expressos em valores $\varphi$ ("phi" $=-\log _{2}$ diâmetro $\mathrm{mm}$ ).

Durante cada amostragem também foi medido o regime de ondas atuantes. A altura da onda $(\mathrm{Hb})$ foi estimada visualmente, no momento imediatamente anterior à sua quebra. O período da onda $(\mathrm{T})$ foi estimado com auxílio de um cronômetro e correspondeu a 1/10 do tempo total transcorrido para a passagem de onze cristas consecutivas em um ponto fixo na zona de surfe. Três observações foram realizadas em cada coleta para a obtenção de uma média. Posteriormente, uma saída a campo, percorrendo todos os pontos, foi realizada para a obtenção de dados sobre o regime de ondas atuando nas praias durante um período de maré alta, conforme a mesma metodologia descrita acima.

Para cada praia foram computados os índices $\Omega$ (equação 1) e RTR, e o estado morfodinâmico das praias estuarinas foi obtido após plotagem desses valores sobre o modelo bi-dimensional proposto por Masselink \& Short (1993). Os valores de velocidade média de decantação da partícula de sedimento utilizados para o cálculo de $\Omega$ foram obtidos a partir das tabelas de Gibbs et al. (1971).

RESULTADOS Os perfis topográficos das praias estuarinas estudadas podem ser visualizados nas figuras 2 e 3. De uma forma geral, as praias caracterizaram-se por apresentar uma estreita (entre 10 e $41 \mathrm{~m}$ de largura) e íngreme (entre 2,6 e $8,3^{\circ}$ de declividade) porção superior ou face praial, seguida por uma planície de maré em sua porção inferior, com extensões variando entre $17 \mathrm{e}$ $>150$ metros e com declividades entre 0,14 e $2^{\circ}$ (Figs. 2 e 3, Tab. 1). As únicas exceções foram as praias Ponta do Poço, Cobras e Vila (respectivamente pontos 3, 5 e 12 da Fig. 1), onde não ocorreu a formação da planície.

A diferenciação entre a face praial e a planície foi facilmente observada pela marcada quebra no perfil topográfico da praia (Fig. 4a). Distintas feições topográficas também puderam ser observadas entre esses dois subambientes. Enquanto a face praial é praticamente plana, a presença de pequenas marcas de ondulação ("ripple marks") é comum ao longo da planície (Fig. 4b). Outras feições morfológicas na planície, como a 
presença de bancos, cavas e marcas de correntes de retorno, ocorreram somente nas praias Techint, Coroazinha e Cemitério (Figs. 2, 3 e 4c-f).

Em relação a granulometria, a face praial é composta por areia fina muito bem selecionada a areia grossa pobremente selecionada, com porcentagem de frações finas sempre inferior a $4 \%$, sendo ainda observado um aumento no diâmetro médio do grão seguido de uma redução no grau de seleção ao longo das praias em direção ao interior do estuário (Tab. 1). Diferenças na composição granulométrica da planície também foram observadas entre as praias, sendo que os ambientes localizados próximos à desembocadura apresentaram uma planície arenosa (frações finas $<10 \%$ ) enquanto que as praias mais internas (i.e., Piaçaguera, Europinha, Pita e Gamelas) tiveram planícies areno-lodosas com frações finas $>30 \%$ (Tab. 1).

As observações de onda revelaram que as praias, tanto na baixamar quanto na preamar, estão sob a ação de ondas de baixa amplitude $(\mathrm{Hb}<0,35 \mathrm{~m})$ e período curto $(\mathrm{T}<4,3 \mathrm{~s})$. No entanto, durante o período de maré baixa, apenas as praias localizadas próximas à desembocadura da baía sofreram a ação das ondas, as quais foram ligeiramente menores do que as ondas atuantes durante o período de preamar (Tab. 2). Numa comparação entre as praias pode ser observada uma marcada redução na amplitude e no período das ondas em direção ao interior do estuário, sugerindo a formação de um gradiente de energia ao longo do mesmo (Tab. 2).

Em decorrência da ausência de ondas em muitas praias durante o período de maré baixa, os índices morfodinâmicos foram computados somente com os dados de onda atuantes durante a preamar. No entanto, optou-se por utilizar o valor médio dos dados granulométricos de verão e de inverno para o cálculo do índice de $\Omega$. Este índice apresentou valores variando entre 0,2 (Pita) e 3,3 (Techint) enquanto que os valores de RTR variaram entre 5,5 (Techint) a 54,8 (Pita). Com base no modelo morfodinâmico adotado, as praias estuarinas estudadas foram agrupadas entre ambientes modificados por maré $(3<\mathrm{RTR}<15)$ e ambientes dominados por maré com transição para planície de maré (RTR > 15; Fig. 5). No grupo das praias modificadas por maré, prevaleceu o estágio de praia "refletiva com terraço de maré baixa", com exceção da praia Techint, a qual correspondeu ao estágio "intermediário com bancos e correntes de retorno de maré baixa" (Fig. 5).

DISCUSSÕES E CONCLUSÃO De uma forma geral, as praias estuarinas da Baía de Paranaguá apresentaram uma morfologia muito similar entre si, sendo elas compostas por uma estreita e íngreme face praial seguida por uma planície, geralmente extensa e plana, em sua porção inferior. Este perfil morfológico tem sido descrito como o típico para praias estuarinas com elevada influência mareal (Nordstrom 1992, Jackson et al. 2002, Freire et al. 2007). Entretanto, em três locais (Ponta do Poço, Vila e Cobras) não houve a formação da planície na parte inferior da praia. Com exceção de Cobras, as outras duas praias localizam-se nas bordas de canais, onde, além de
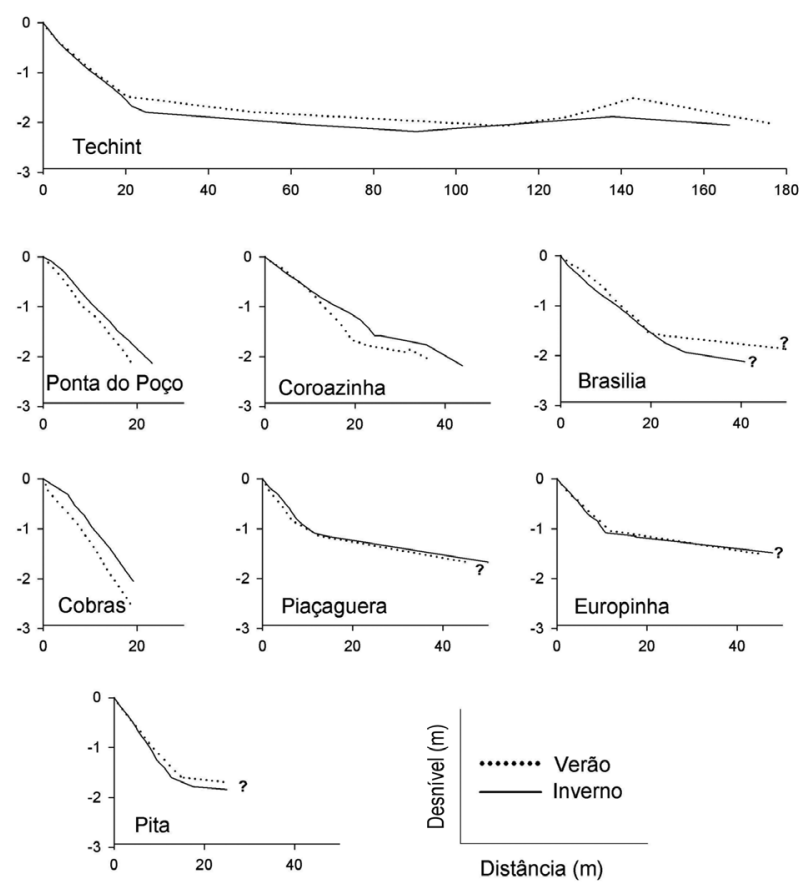

Figura 2 - Perfil topográfico das praias estuarinas localizadas ao longo do eixo leste-oeste da baía (pontos 1-8) obtidos durante o ano de 2004. O sinal de interrogação (?) indica que a extensão total da planície não foi medida.
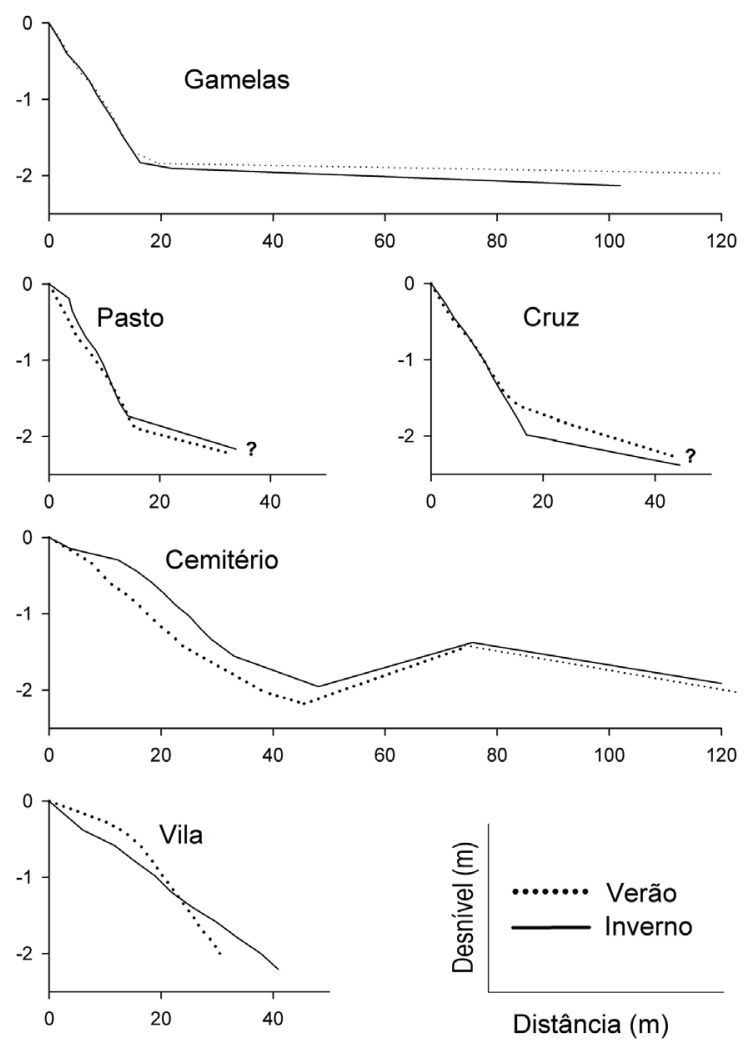

Figura 3 - Perfil topográfico das praias estuarinas localizadas ao longo do eixo norte-sul da baía (pontos 9-13) obtidos durante o ano de 2005. O sinal de interrogação (?) indica que a extensão total da planície não foi medida. 
Tabela 1 - Características morfológicas e sedimentares da porção superior (face praial) e inferior (planície de maré) das praias estuarinas localizadas na Baía de Paranaguá durante as situações de verão (Ver) e de inverno (Inv) de 2004 (P1 a P8) e de 2005 (P9 a P13). * Média ( \pm Desvio Padrão) calculado a partir das amostras coletadas ao longo da face praial $(n=10)$ e da planície $(n=2)$.

\begin{tabular}{|c|c|c|c|c|c|c|c|c|c|c|c|}
\hline \multirow{2}{*}{ Praia/ Período } & & \multicolumn{5}{|c|}{ Face praial } & \multicolumn{5}{|c|}{ Planície } \\
\hline & & $\begin{array}{l}\text { Largura } \\
(\mathrm{m})\end{array}$ & $\begin{array}{c}\text { Inclinação } \\
\left({ }^{\circ}\right)\end{array}$ & $\begin{array}{c}\text { Tamanho do } \\
\text { grão }(\varphi)^{*}\end{array}$ & $\begin{array}{c}\text { Grau de } \\
\text { seleção }(\varphi)^{*}\end{array}$ & $\begin{array}{c}\text { Finos } \\
(\%)\end{array}$ & $\begin{array}{c}\text { Largura } \\
(\mathrm{m})\end{array}$ & $\begin{array}{c}\text { Inclinação } \\
\left({ }^{\circ}\right)\end{array}$ & $\begin{array}{c}\text { Tamanho do } \\
\text { grão }(\varphi)^{*}\end{array}$ & $\begin{array}{c}\text { Grau de } \\
\text { seleção }(\varphi)^{*}\end{array}$ & $\begin{array}{c}\text { Finos } \\
\%\end{array}$ \\
\hline \multirow[t]{2}{*}{ Brasília (P1) } & Ver & 19,5 & 4,6 & $2,3( \pm 0,3)$ & $0,6( \pm 0,3)$ & 2,6 & $>25$ & 0,6 & $2,7( \pm 0,2)$ & $0,4( \pm 0,2)$ & 2,9 \\
\hline & Inv & 27,7 & 3,8 & $2,6( \pm 0,1)$ & $0,4( \pm 0,1)$ & 2,3 & $>10$ & 0,8 & $2,7( \pm 0,1)$ & $0,3( \pm 0,2)$ & 3,4 \\
\hline \multirow[t]{2}{*}{ Techint (P2) } & Ver & 20,2 & 4,0 & $2,0( \pm 0,5)$ & $0,8( \pm 0,2)$ & 3,3 & 156,2 & 0,2 & $2,1( \pm 0,5)$ & $0,4( \pm 0,2)$ & 5,6 \\
\hline & Inv & 21,4 & 4,5 & $2,4( \pm 0,4)$ & $0,7( \pm 0,3)$ & 3,8 & 145 & 0,15 & $2,7( \pm 0,2)$ & $0,7( \pm 0,3)$ & 9,8 \\
\hline \multirow[t]{2}{*}{ P. Poço (P3) } & Ver & 17,6 & 6,3 & $2,6( \pm 0,1)$ & $0,4( \pm 0,1)$ & 2,9 & - & - & - & - & - \\
\hline & Inv & 20,6 & 5,5 & $2,7( \pm 0,2)$ & $0,4( \pm 0,1)$ & 3,3 & - & - & - & - & - \\
\hline \multirow[t]{2}{*}{ Coroazinha (P4) } & Ver & 19,2 & 5,0 & $2,2( \pm 0,1)$ & $0,5( \pm 0,1)$ & 3,4 & 17,6 & 0,6 & $2,4( \pm 0,2)$ & $0,5( \pm 0,1)$ & 5,4 \\
\hline & Inv & 24,3 & 3,7 & $2,4( \pm 0,1)$ & $0,4( \pm 0,1)$ & 1,6 & 19,5 & 0,7 & $2,3( \pm 0,1)$ & $0,6( \pm 0,2)$ & 2,4 \\
\hline \multirow[t]{2}{*}{ Cobras (P5) } & Ver & 17 & 7,3 & $1,0( \pm 0,3)$ & $0,6( \pm 0,2)$ & 3,5 & - & - & - & - & - \\
\hline & Inv & 19,2 & 6,4 & $1,1( \pm 0,2)$ & $0,5( \pm 0,1)$ & 2,6 & - & - & - & - & - \\
\hline \multirow[t]{2}{*}{ Piaçaguera (P6) } & Ver & 12,7 & 4,4 & $2,0( \pm 0,3)$ & $0,5( \pm 0,1)$ & 4,0 & $>32,8$ & 0,9 & $2,0( \pm 0,5)$ & $0,5( \pm 0,2)$ & 41,5 \\
\hline & Inv & 11,6 & 5,2 & $1,9( \pm 0,2)$ & $0,4( \pm 0,1)$ & 1,2 & 70 & 0,8 & $2,1( \pm 0,7)$ & $0,4( \pm 0,3)$ & 36,5 \\
\hline \multirow[t]{2}{*}{ Europinha (P7) } & Ver & 11,8 & 5,1 & $0,7( \pm 0,2)$ & $1,0( \pm 0,1)$ & 2,9 & $>33$ & 0,8 & $1,2( \pm 0,7)$ & $1,4( \pm 0,8)$ & 42 \\
\hline & Inv & 10,8 & 5,7 & $0,1( \pm 0,2)$ & $1,1( \pm 0,1)$ & 2,4 & $>30$ & 0,8 & $1,4( \pm 0,8)$ & $1,2( \pm 0,7)$ & 40 \\
\hline \multirow[t]{2}{*}{ Pita (P8) } & Ver & 15,1 & 5,9 & $0,6( \pm 0,3)$ & $1,2( \pm 0,4)$ & 2,0 & $>15$ & 0,6 & $0,5( \pm 0,6)$ & $1,5( \pm 0,5)$ & 42,5 \\
\hline & Inv & 12,8 & 7,2 & $0,1( \pm 0,3)$ & $1,3( \pm 0,3)$ & 1,6 & $>15$ & 0,6 & $1,8( \pm 1,0)$ & $1,6( \pm 0,6)$ & 40,1 \\
\hline \multirow[t]{2}{*}{ Gamelas (P9) } & Ver & 15 & 6,5 & $0,9( \pm 0,8)$ & $1,0( \pm 0,4)$ & 0,5 & 121,5 & 0,14 & $2,5( \pm 0,3)$ & $0,8( \pm 0,4)$ & 30 \\
\hline & Inv & 16,3 & 6,4 & $1,1( \pm 0,4)$ & $0,9( \pm 0,2)$ & 2,0 & 86 & 0,2 & $2,3( \pm 0,2)$ & $0,7( \pm 0,3)$ & 40,5 \\
\hline \multirow[t]{2}{*}{ Pasto (P10) } & Ver & 15,56 & 6,5 & $1,9( \pm 0,5)$ & $0,5( \pm 0,1)$ & 1,2 & $>15$ & 1,2 & $1,9( \pm 0,5)$ & $0,5( \pm 0,1)$ & 4,3 \\
\hline & Inv & 14.21 & 8,3 & $1,6( \pm 0,4)$ & $0,6( \pm 0,2)$ & 1,0 & $>20$ & 1,2 & $2,3( \pm 0,5)$ & $0,8( \pm 0,3)$ & 3,4 \\
\hline \multirow[t]{2}{*}{ Cruz (P11) } & Ver & 13,14 & 6,2 & $1,8( \pm 0,3)$ & $0,8( \pm 0,2)$ & 0,4 & $>10$ & 2,0 & $1,5( \pm 0,3)$ & $0,8( \pm 0,5)$ & 3,6 \\
\hline & Inv & 17,06 & 6,8 & $1,7( \pm 0,3)$ & $0,9( \pm 0,2)$ & 0,8 & $>6$ & 0,7 & $2,4( \pm 0,3)$ & $1,4( \pm 0,5)$ & 2,8 \\
\hline \multirow[t]{2}{*}{ Vila (P12) } & Ver & 30,87 & 5,4 & $2,5( \pm 0,2)$ & $0,5( \pm 0,1)$ & 2,0 & - & - & - & - & - \\
\hline & Inv & 40,88 & 3,0 & $2,5( \pm 0,1)$ & $0,4( \pm 0,1)$ & 1,9 & - & - & - & - & - \\
\hline \multirow[t]{2}{*}{ Cemitério (P13) } & Ver & 23,93 & 3,6 & $2,7( \pm 0,1)$ & $0,4( \pm 0,1)$ & 1,8 & 100 & 0,4 & $2,8( \pm 0,1)$ & $0,5( \pm 0,2)$ & 4,5 \\
\hline & Inv & 38,99 & 2,6 & $2,5( \pm 0,1)$ & $0,4( \pm 0,1)$ & 1,5 & 102 & 0,4 & $2,6( \pm 0,2)$ & $0,3( \pm 0,1)$ & 5,3 \\
\hline
\end{tabular}

uma maior profundidade, os efeitos das fortes correntes de maré provavelmente inibiram a formação de um ambiente de planície.

Adicionalmente, baseado nas diferenças obser- vadas, principalmente aquelas relacionadas à geometria do perfil e a presença de outras feições morfológicas ao longo da planície, poderíamos identificar dois principais grupos morfológicos. Num primeiro grupo estariam as 


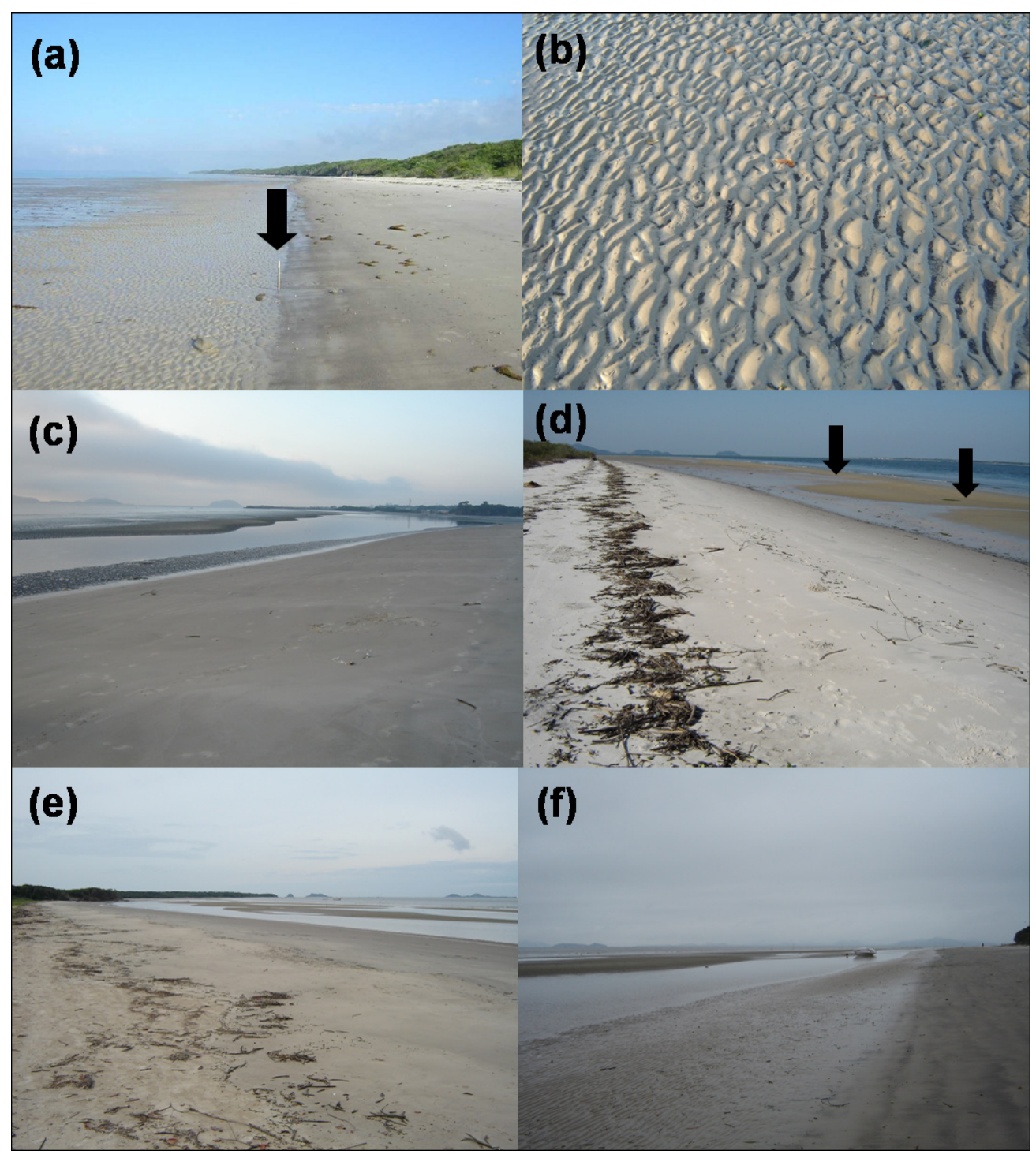

Figura 4 - Fotografias de algumas praias e suas feições topográficas mencionadas ao longo do texto. (a) Brasília (ponto 1) indicando o quebra no perfil, a qual corresponde ao limite entre a face praial e a planície de maré e (b) detalhe da micro-topografia da planicie; (c-f) praias com presença de cavas e bancos formados ao longo da planície de maré. (c) Techint (ponto 2); (d) Coroazinha (ponto 4) indicando áreas com correntes de retorno e (e-f) Cemitério (ponto 13).

praias localizadas próximas a desembocadura, as quais apresentam uma face praial geralmente convexa e/ou com a presença de bancos e cavas na planície associada. Alterações morfológicas sazonais, como as observadas em Vila e Cemitério (Fig. 3), onde a face praial variou entre formatos plano e convexo, podem ser comuns a esse grupo morfológico de praia estuarina. Já o segundo grupo, corresponderia às praias localizadas mais internamente, as quais apresentaram perfis retilíneos, tanto da face praial quanto da planície, e onde não foi observada a presença de bancos ou cavas ao longo da planície.

A composição sedimentar da face praial variou entre areia fina muito bem selecionada a areia grossa pobremente selecionada, sendo que esse aumento no diâmetro do grão seguido pela redução do grau de seleção dos sedimentos foi observado ao longo das praias em direção ao interior da baía. Tal padrão de mudança na composição sedimentar tem sido descrito para as praias estuarinas de Tagus (Portugal), onde se verificou que as características granulométricas das faces praiais estão muito mais relacionadas à fonte do sedimento do que ao morfodinamismo local (Freire et al. 2006, 2007). As praias localizadas próximas à desembocadura do Tagus são compostas por areia fina muito bem selecionada, semelhantes as praias oceânicas adjacentes, indicando assim a origem marinha do sedimento. Por outro lado, sedimentos grosseiros e principalmente com baixo grau de seleção indicariam que a formação das praias estuarinas nas regiões internas é resultante de depósitos fluviais (Freire et al. 2007). Na Baía de Paranaguá, presença de bancos arenosos compostos principalmente por partículas grosseiras e pobremente selecionadas são comuns na 
Tabela 2 - Regime de ondas atuante nas praias estuarinas localizadas na Baía de Paranaguá durante as situações de baixamar e preamar. $H b=$ altura da onda, $T=$ periodo. *Amplitude (dados Lab. Oc. Fisica/CEM).

\begin{tabular}{|c|c|c|c|c|c|}
\hline \multirow{2}{*}{ Praia } & \multicolumn{2}{|c|}{ Baixamar } & \multicolumn{2}{|c|}{ Preamar } & \multirow{2}{*}{$\begin{array}{l}\text { Maré } \\
(\mathrm{m})^{*}\end{array}$} \\
\hline & $\mathrm{Hb}(\mathrm{m})$ & $\mathrm{T}(\mathrm{s})$ & $\mathrm{Hb}(\mathrm{m})$ & $\mathrm{T}(\mathrm{s})$ & \\
\hline Brasília (P1) & 0,10 & 3,3 & 0,20 & 3,7 & 1,92 \\
\hline Techint (P2) & 0,25 & 4,3 & 0,35 & 3,1 & 1,92 \\
\hline P. Poço (P3) & 0,10 & 4,3 & 0,15 & 3,6 & 1,92 \\
\hline Coroazinha (P4) & 0,10 & 3,3 & 0,15 & 3,2 & 1,92 \\
\hline Cobras (P5) & 0,20 & 3,3 & 0,15 & 2,3 & 2,07 \\
\hline Piaçaguera (P6) & 0 & 0 & 0,08 & 2,2 & 2,09 \\
\hline Europinha (P7) & 0 & 0 & 0,08 & 2,5 & 2,42 \\
\hline Pita (P8) & 0 & 0 & 0,05 & 2,0 & 2,74 \\
\hline Gamelas (P9) & 0 & 0 & 0,08 & 3,6 & 2,10 \\
\hline Pasto (P10) & 0 & 0 & 0,12 & 2,1 & 2,07 \\
\hline Cruz (P11) & 0 & 0 & 0,20 & 3,1 & 2,07 \\
\hline Vila (P12) & 0,10 & 2,3 & 0,15 & 4,2 & 1,84 \\
\hline Cemitério (P13) & 0,15 & 3,7 & 0,28 & 4,2 & 1,84 \\
\hline
\end{tabular}

porção superior da baía devido ao aporte fluvial de sedimentos (Bigarella et al. 1978, Lamour et al. 2004), o qual tem aumentado significativamente nos últimos anos em decorrência de interferências antrópicas (Odreski et al. 2003). Esses depósitos podem ser considerados como a principal fonte de sedimento para a formação dos ambientes praiais nos setores mais internos da baía.

Nas praias localizadas próximas a desembocadura da Baía de Paranaguá, tanto a face praial quanto a planície apresentaram características granulométricas semelhantes entre si, sendo ambas compostas por areia fina muito bem selecionada. Por outro lado, a medida que adentramos na baía a composição sedimentar desses dois subambientes começa a divergir. Enquanto que os sedimentos da face praial tornam-se mais grossos, as planícies tornam-se mais lamosas (proporção de finos > $40 \%$ em direção ao interior do estuário. Tais diferenças na composição sedimentar dos dois subambientes refletem a baixa (ou nula) troca de sedimento entre a face praial e a planície (Nordstrom 1992, Jackson \& Nordstrom 1992). Conseqüentemente, é bem provável que cada um dos componentes tenha sua própria fonte de sedimento. Características sedimentares de fundo (Bigarella et al. 1978) e de áreas de marisma (Netto $\&$ Lana 1996) localizadas ao longo do eixo leste-oeste da baía mostram a presença de dois setores distintos. O primeiro setor corresponde a área entre Ilha do Mel e Paranaguá, onde os sedimentos são compostos por areia fina bem selecionada e baixo teor de matéria orgânica refletindo o domínio marinho. Já o segundo setor, de Paranaguá a Antonina, corresponde ao domínio estuarino com sedimentos lamosos pobremente selecionados.

As praias estuarinas são consideradas ambientes de baixa energia, conseqüentemente, as ondas atuantes nesses ambientes caracterizam-se por apresentarem bai-

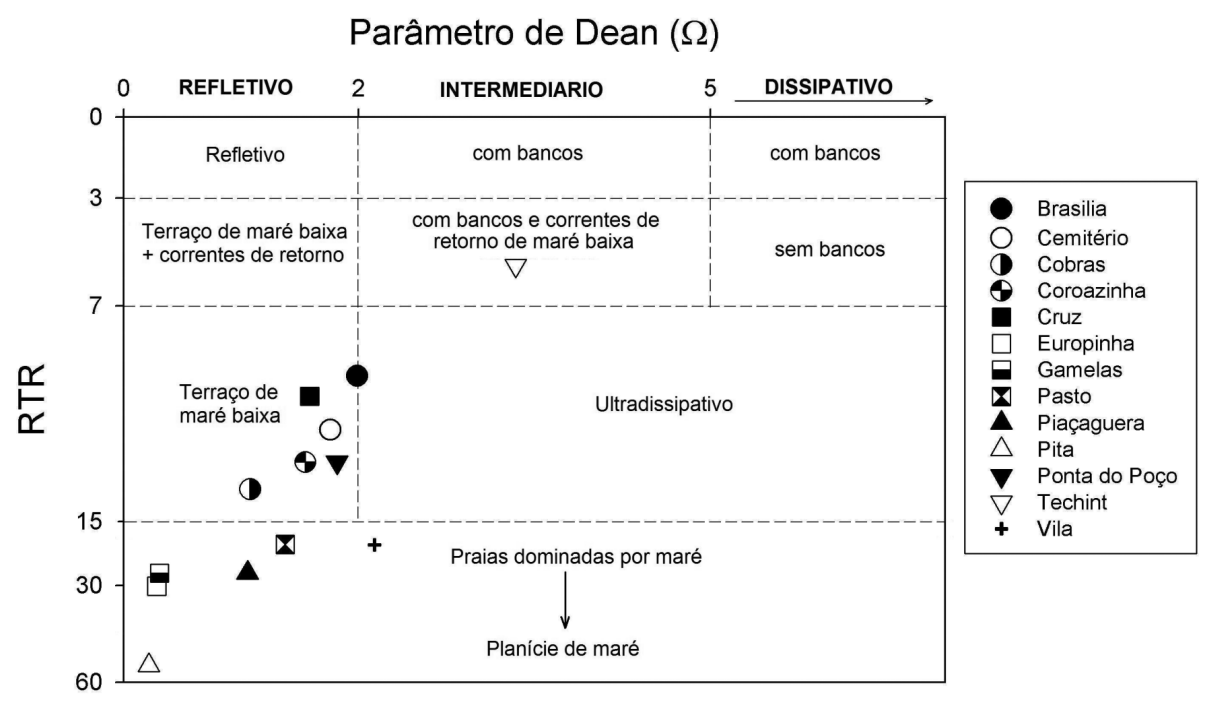

Figura 5 - Diagrama de dispersão dos valores do parâmetro de Dean ( $\Omega$ ) versus RTR computados para as praias estuarinas da Baía de Paranaguá plotados contra o modelo morfodinâmico proposto por Masselink \& Short (1993). 
xa altura $(\mathrm{Hb}<0,25 \mathrm{~m})$ e período curto $(\mathrm{T}<5 \mathrm{~s})$, este último característico de ondas geradas localmente dentro de uma pista limitada (Jackson et al. 2002). Diferenças como as observadas no regime de ondas ao longo de um ciclo de maré também são comuns nesses ambientes (Nordstrom 1992). Geralmente, durante a maré baixa, a energia da onda é dissipada ao longo de toda a extensão da planície, dificultando assim sua observação e quantificação. Com a subida da maré, tão logo a coluna d'água atinge altura suficiente para que a planície não ofereça mais resistência, as ondas começam a quebrar sobre a face praial. No entanto, a presença de ondas atuando sobre as praias localizadas próximas a desembocadura da baía, mesmo durante a maré baixa, mostra a influência de ondas oceânicas refratadas que penetram dentro do estuário. Por outro lado, a influência destas ondas diminui a medida que adentramos no estuário, e as praias começam a ser afetadas somente pela ação de ondas geradas localmente. Conseqüentemente, o gradiente decrescente de energia observado é resultado da redução na contribuição das ondas oceânicas sobre o regime atuante nas praias estuarinas mais internas.

Embora sendo um ambiente micromareal (amplitude máxima de $2 \mathrm{~m}$ ), a razão entre a amplitude de maré e a altura das ondas atuantes resultou em elevados valores de RTR ( $>3$ ) para todas as praias estuarinas estudadas na Baía de Paranaguá, classificando-as entre ambientes modificados a dominados pela ação da maré, o que de certa maneira, reflete o gradiente morfológico e energético descrito acima. No entanto, os grupos morfológicos formados pela aplicação do modelo proposto não corresponderam totalmente com as morfologias observadas em campo. A praia Techint apresentou uma porção superior refletiva associada a uma planície de maré extensa com bancos rítmicos e canais de correntes de retorno na porção inferior, corroborando com o morfotipo proposto pelo modelo. Por outro lado, embora morfologicamente semelhantes a praia Techint, as praias Cemitério e Coroazinha foram agrupadas juntamente com as praias Brasília, Ponta do Poço, Cobras e Cruz como refletiva com terraço de maré baixa, no qual não ocorreria a formação de bancos ou canais. Como era de se esperar para morfotipos estabelecidos a partir de índices que consideram apenas valores de amplitude de onda, maré e granulometria do sedimento, algumas praias, mesmo não apresentando uma planície associada, foram classificadas como refletiva com terraço de maré baixa (i.e., Ponta do Poço e Cobras) ou como transição entre dominadas por maré e planícies mareais (Praia Vila). No entanto, cabe ressaltar que os dados de altura e de período de onda utilizados foram de apenas uma observação (pontuais), o que pode ter limitado a eficiência do modelo na classificação dos estados morfodinâmicos.

A aplicação de modelos morfodinâmicos, que foram originalmente desenvolvidos para ambientes de alta energia, para caracterizar ambientes de baixa energia como as praias estuarinas estudadas, tem sido duramente criticada por vários autores que acharam a sua aplicação ineficiente (Nordstrom 1992, Hegge et al. 1996, Masselink \& Pattiaratchi 2001, Jackson et al.
2002, Eliot et al. 2006, Travers 2007). As praias estuarinas de baixa energia diferem das praias oceânicas expostas em muitos outros aspectos, não podendo ser considerados apenas como diferentes em termos de escala de energia (Travers 2007). Por exemplo, as variações cíclicas do perfil topográfico, que são típicas nas praias oceânicas, estão ausentes nas praias estuarinas. A evolução a médio e longo prazo desses ambientes parece também depender, sobretudo, da ocorrência de eventos extremos de baixa freqüência (Freire \& Andrade 1999, Jackson et al. 2002, Kennedy 2002). Como alternativa, tem sido proposto que as praias em ambientes de baixa energia somente podem ser classificadas com relação a sua morfologia (Hegge et al. 1996, Makaske \& Augustinus 1998, Jackson et al. 2002, Travers 2007).

Porém, numa recente caracterização das praias australianas Short (2006) re-avaliou os limites de RTR preestabelecidos pelo modelo de Masselink \& Short (1993), tendo como base grupos morfológicos de praias. Embora tenham sido confirmados os limites para as praias dominadas por onda $(\mathrm{RTR}<3)$ e para as modificadas por maré $(3<$ RTR $<15)$, verificou-se que as praias dominadas por maré podem ocorrem num intervalo de RTR entre 12 e 50, sendo que acima desse limite não haveria mais formação de ambiente de praia e planícies intermareais dominariam (Short 2006). Segundo o autor, as praias dominadas por maré ocorrem em locais protegidos e sofrem a ação de ondas de baixa amplitude $(\mathrm{Hb}<$ $0,26 \mathrm{~m}$ ). Essas praias caracterizam-se por apresentar uma estreita e íngreme porção superior arenosa, uma marcada quebra no perfil e uma extensa planície com gradiente suave e sem feições morfológicas na parte inferior. Embora morfologicamente semelhantes dois tipos de praias dominadas por maré podem ser distinguidos com base na composição sedimentar da porção inferior (i.e., refletiva + planície arenosa ou refletiva + planície lamosa).

A maioria das praias estuarinas estudadas aqui, principalmente aquelas agrupadas como ambientes dominados por maré numa transição para planícies mareais (Fig. 5), compartilham das características descritas acima. Conseqüentemente, embora a aplicação do modelo morfodinâmico tenha sido limitada pela qualidade dos dados de onda utilizados (i.e., dados pontuais de uma única observação), os perfis morfológicos observados nas praias da Baia de Paranaguá correspondem aos morfotipos descritos na literatura, principalmente com os perfis de praias dominadas por maré descritos por Short (2006). Um segundo grupo morfológico observado englobaria as praias localizadas próximas a região de desembocadura, as quais estariam sobre a influência de ondas oceânicas refratadas e forte influência de correntes de maré. Essas praias são caracterizadas por apresentarem um perfil formado por uma face praial curta e íngreme, a qual pode variar entre formatos planos e convexos, seguido por uma planície onde ocorre a presença de bancos, canais e locais de correntes de retorno, ou mesmo ausência da planície devido aos efeitos das fortes correntes de marés as quais esses ambientes estão sujeitos quando próximos a canais de maré vazante. 


\section{Referências}

Angulo R.J. 1999. Morphological characterization of the tidal deltas on the coast of the State of Paraná. An. Acad. Bras. Ci., 71:935-959.

Angulo R.J. \& Araújo A.D. 1996. Classificação da costa paranaense com base na sua dinâmica como subsídio à ocupação da orla litorânea. Bol. Par. Geoc., 44:7-17.

Bigarella J.J., Becker R.D., Matos D.J., Werner A. 1978. A Serra do Mar e a porção oriental do Estado do Paraná. Curitiba, Secretária de Estado do Planejamento, Governo do Paraná, 248p.

Borzone C.A., Melo S.G., Rezende K.V., Vale R., Krul R. 2003. Macrobenthic intertidal communities from wave to tide dominated beaches environment: a case of two Brazilian beaches. J. Coast. Res., SI 35:472-480.

Dean R.G. 1973. Heuristic models of sand transport in the surf zone. In: Conferences on engineering dynamics in the surf zone, Sydney, NSW, Proceeding, p. 208-214.

Eliot M.J., Travers A., Eliot I. 2006. Morphology of a lowenergy beach, Como Beach, Western Australia. J. Coast. Res., 22:63-77.

Freire P. \& Andrade C. 1999. Wind-induced sand transport in Tagus estuarine beaches: first results. Aquat. Ecol., 33:225-233.

Freire P., Taborda R., Andrade C. 2006. Caracterização das praias estuarinas do Tejo. In: APRH, Congresso da Água, 8, Figueira da Foz, CD-Rom.

Freire P., Taborda R., Silva A.M. 2007. Sedimentary characterization of Tagus estuarine beaches (Portugal). A contribution to the sediment budget assessment. J. Soils Sediments, 7:296-302.

Gibbs R.J., Matthews M.D. \& Link D.A. 1971. The relationship between sphere size and settling velocity. J. Sediment. Petrol., 41:7-18.

Hegge B.J., Eliot I., Hsu J. 1996. Sheltered sandy beaches of southwestern Australia. J. Coast. Res., 12:748-760.

Jackson N.L. \& Nordstrom K.F. 1992. Site-specific controls on wind and wave processes and beach mobility on estuarine beaches. J. Coast. Res., 8:88-98.

Jackson N.L., Nordstrom K.F., Eliot I., Masselink G. 2002. "Low-energy" sandy beaches in marine and estuarine environments: a review. Geomorphology, 48:147-162.

Kennedy D.M. 2002. Estuarine beach morphology in microtidal Middle Harbour, Sydney. Aust. Geog. Stud., 40:231-240.

Knoppers B.A., Brandini F.P., Thamm C.A. 1987. Ecological studies in the Bay of Paranaguá. II- Some physical and chemical chacteristics. Nerítica, 2:1-36.

Lamour M.R., Soares C.R., Carrilho J.C. 2004. Mapas de parâmetros texturais de sedimentos de fundo do Complexo Estuarino de Paranaguá - PR. Bol. Par. Geoc., 55:77-82.

Lana P.C., Morone E., Lopes R.M., Machado E.C. 2001. The Subtropical Estuarine Complex of Paranaguá Bay, Brazil. In: Seeliger U. \& Kjerfve B. (eds.) Coastal Marine Ecosystems of Latin America. Berlin, Springer-Verlag, p. 131-145.

Mantovanelli A., Marone E., da Silva E.T., Lautert L.F., Klingenfuss M.S., Prata-Jr V.P., Noernberg M.A., Knoppers B.A. \& Ângulo R.J. 2004. Combined tidal velocity and duration asymmetries as a determinant of water transport and residual flow in Paranaguá Bay estuary. Estuar. Coast. Shelf Sci., 59:523-537.

Marone E. \&_Camargo R. 1994. Marés meteorológicas no litoral do Estado do Paraná: o evento de 18 de agosto de 1993. Nerítica, 8:73-85.

Marone E. \& Jamiyanaa D. 1997. Tidal characteristics and a numerical model for the $\mathrm{M}_{2}$ tide at the estuarine complex of the Bay of Paranaguá, Paraná, Brazil. Nerítica, 11:95107.

Makaske B. \& Augustinus G.E.F. 1998. Morphologic changes of a micro-tidal, low wave energy beach face during a spring-neap cycle, Rhone Delta, France. J. Coast. Res., 14:632-645.

Masselink G. \& Pattiaratchi C.B. 2001. Seasonal changes in beach morphology along the sheltered coastline of Perth, Western Australia. Mar. Geol., 172:243-263.

Masselink G. \& Short A.D. 1993. The effects of tide range on beach morphodynamics and morphology: a conceptual beach model. J. Coast. Res., 9:785-800.

Netto S.A. \& Lana P.C. 1996. Benthic macrofauna of Spartina alterniflora marshes and nearby unvegetated tidal flats of Paranaguá Bay (SE Brazil). Nerítica, 10:41-56.

Nordstrom K.F. 1992. Estuarine beaches. London, Elsevier Applied Science, 225p.

Nordstrom K.F. \& Jackson N.L. 1992. Two-dimensional changes on sandy beaches in meso-tidal estuaries. Z. Geomorphol., 36:465-478.

Odreski L.L.R., Soares C.R., Angulo R. J., Zem, R.C. 2003. Taxas de assoreamento e a influência antrópica no controle da sedimentação da Baía de Antonina, Paraná. Bol. Par. Geoc., 53:7-12.

Short A.D. 1996. The role of wave height, period, slope, tide range and embaymentisation in beach classifications: a review. Rev. Chil. Hist. Nat., 69:589-604.

Short A.D. 1999. Handbook of beach and shoreface morphodynamics. London, Jonh Wiley, 379p.

Short A.D. 2006. Australian beach systems: nature and distribution. J. Coast. Res., 22:11-27.

Soares C.R., Borzone C.A., Souza J.R.B. 1997. Variações morfológicas e sedimentológicas ao longo de um ciclo anual numa praia arenosa no sul do Brasil. Oecol. Bras., 3:245-258.

Suguio K. 1973. Introdução à sedimentologia. São Paulo, EDUSP, $317 \mathrm{p}$.

Tanner W.F. 1995. Environmental clastic granulometry. Florida Geological Survey, Special Publication no 40, 163p.

Travers A. 2007. Low-energy beach morphology with respect to physical setting: a case study from Cockburn Sound, southwestern Australia. J. Coast. Res., 23:429-444.

Wright L.D. \& Short A.D. 1984. Morphodynamic variability of surf zones and beaches: a synthesis. Mar. Geol., 56:93-118.

Manuscrito ID 11109

Submetido em 15 de abril de 2008 Aceito em 20 de junho de 2008 Sistema eletrônico de submissão 